Louisiana State University

LSU Digital Commons

\title{
A Comparison of Social Skills Profiles in Intellectually Disabled Adults with and without ASD
}

Jonathan Wilkins

Louisiana State University and Agricultural and Mechanical College

Follow this and additional works at: https://digitalcommons.Isu.edu/gradschool_theses

Part of the Psychology Commons

\section{Recommended Citation}

Wilkins, Jonathan, "A Comparison of Social Skills Profiles in Intellectually Disabled Adults with and without ASD" (2007). LSU Master's Theses. 3633.

https://digitalcommons.Isu.edu/gradschool_theses/3633

This Thesis is brought to you for free and open access by the Graduate School at LSU Digital Commons. It has been accepted for inclusion in LSU Master's Theses by an authorized graduate school editor of LSU Digital Commons. For more information, please contact gradetd@lsu.edu. 
A COMPARISON OF SOCIAL SKILLS PROFILES IN INTELLECTUALLY DISABLED ADULTS WITH AND WITHOUT ASD

\author{
A Thesis \\ Submitted to the Graduate Faculty of the \\ Louisiana State University and \\ Agricultural and Mechanical College \\ in partial fulfillment of the \\ requirements for the degree of \\ Master of Arts \\ in
}

The Department of Psychology

by

Jonathan Wilkins

B.A., Carleton College, 2002

August 2008 


\section{TABLE OF CONTENTS}

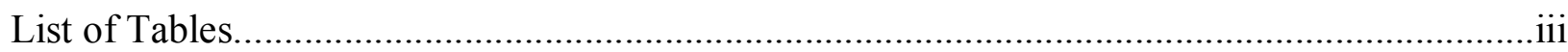

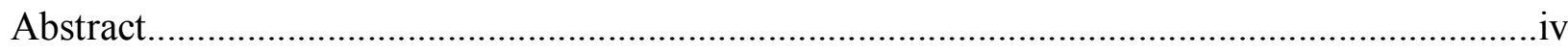

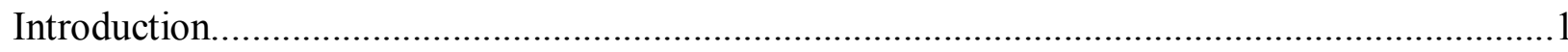

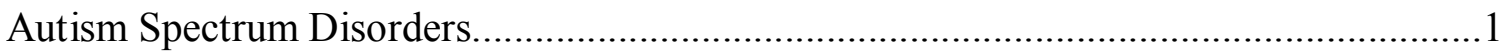

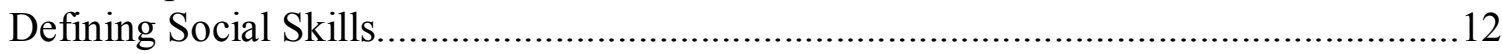

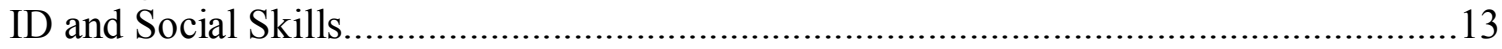

ASD and Social Skills...................................................................................14

Assessment of Social Skills....................................................................................18

Purpose

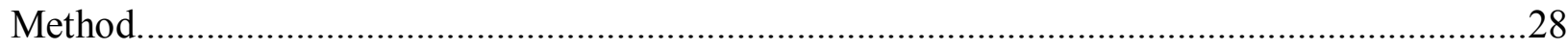

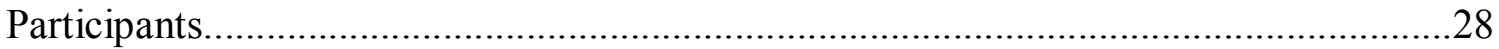

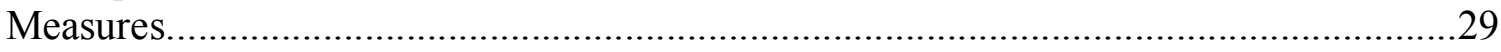

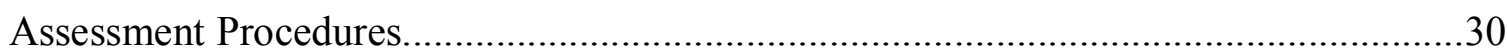

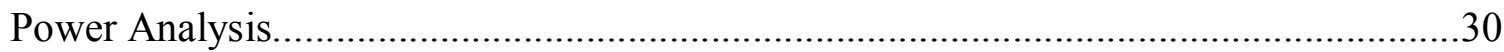

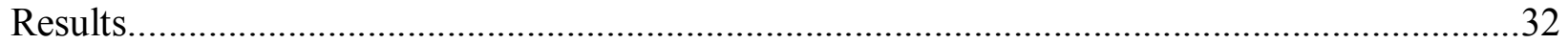

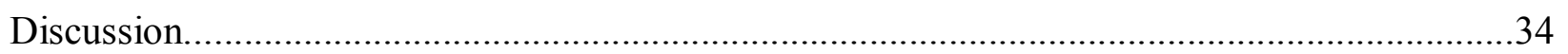

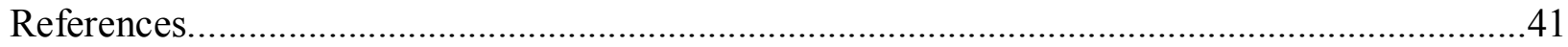

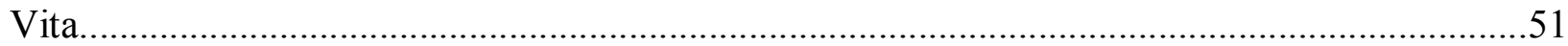




\section{LIST OF TABLES}

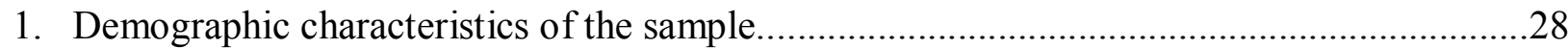

2. Means and standard deviations on the dependent variables for the three groups..................32

3. Percent endorsed on selected items from MESSIER subscales found to

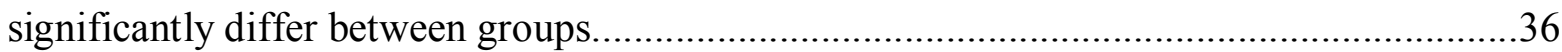




\begin{abstract}
Although there has been a recent increase in research directed toward autism spectrum disorders (ASD), the study of intellectually disabled adults with ASD has gone relatively neglected as efforts have focused largely on young children. Current diagnostic and assessment procedures were created for and validated on this latter group. Many intellectually disabled adults with ASD have not been diagnosed due to the novelty of such instruments and the overlap between symptoms of ASD and severe intellectual disability (ID). A new assessment instrument, the Autism Spectrum Disorders-Diagnostic Scale for Intellectually Disabled Adults (ASD-DA) has been shown to make this fine distinction. The items on this scale pertain to the three areas of impairment found in ASD: communication, socialization, and restricted behavior. Although social deficits associated with ASD have been extensively researched and believed by many to be the defining set of symptoms for the condition, very little is known about the nature of social impairment in adults with both ASD and ID. Distinctions were noted between those with ASD and controls, notably in the areas of positive social behaviors and nonverbal negative social behaviors. Those with autism displayed the greatest deficits in these areas. Implications of the results and directions for future research are discussed.
\end{abstract}




\section{INTRODUCTION}

Impairments in social interaction lie at the core of definitions for both intellectual disability (ID) and autism spectrum disorders (ASD; Matson, 1995; Rutter, 1978; Sevin et al., 1995). Such things as the importance of social norms, the ability to adapt to the environment, and socials skills have been discussed within the field of ID since the beginning of the $20^{\text {th }}$ century (Givens, 1978; Lambert, Wilcox, \& Gleason, 1974). Similarly, impaired social interaction has remained an important component in the diagnosis of ASD since Leo Kanner first described the disorder in 1943. Although diagnosis of ASD has increased greatly in recent years, the condition has always been regarded as a childhood disorder, and consequently, there remains a paucity of research on ASD in adults. The goal of the present study is to provide an in-depth analysis of the nature of social impairment in intellectually disabled adults with ASD. An overview of the history of autism spectrum disorders, symptomology, and relation to intellectual disability is presented along with a discussion of social skills and related assessment techniques.

\section{Autism Spectrum Disorders}

The ASD are a broader class of conditions generally believed to be neurodevelopmental in origin that are characterized by onset in early childhood and deficits in social interaction and communication along with the presence of restricted or repetitive behaviors (Lam, Aman, \& Arnold, 2006; Wing, 1997). The latest edition of the Diagnostic and Statistical Manual of Mental Disorders (DSM-IV-TR) lists them as Pervasive Developmental Disorders. Included among the Pervasive Developmental Disorders are Autistic Disorder, Asperger's syndrome (AS), Pervasive Developmental Disorder-Not Otherwise Specified (PDD-NOS), and two rarer conditions, Childhood Disintegrative Disorder and Rett's Disorder (American Psychiatric 
Association [APA], 2000). These latter two conditions occur with much less frequency and have identifiable biological markers.

History

In Kanner's (1943) initial study of the disorder, he documented a set of behaviors exhibited by 11 children that differentiated them from having any other psychiatric condition. These behaviors included an inability to develop relationships with people, delay in speech acquisition, the noncommunicative use of speech after it was developed, delayed echolalia, pronoun reversal, repetitive and stereotyped play activities, an obsessive insistence on the maintenance of sameness, a lack of imagination, good rote memory, and normal physical appearance. Kanner also recognized that these abnormalities were already present in infancy, which allowed for differentiation from childhood schizophrenia or psychosis. The combination of these traits has often been termed "Kanner's autism" or "classic autism" in the literature. At the heart of his definitions are deficits in social behavior, and this focus has been retained by current classification systems such as the DSM-IV-TR and International Classification of Diseases-10 ${ }^{\text {th }}$ Edition (ICD-10; APA, 2000; World Health Organization [WHO], 1992). In his paper, Kanner documented multiple reports from parents describing their children's lack of interest in the activities of other adults and children they encountered at home or in their neighborhoods. Kanner also witnessed these types of events firsthand as he noted that the children focused exclusively on objects, completely ignoring the people in the room. In situations where they were forced to interact with other people, these children displayed annoyance, resentment, and anger. He referred to the children as having an "autistic disturbance of affective contact." 
The term autism led to some confusion as Bleuler (as cited in Rutter, 1978) had previously used it in reference to the active withdrawal into fantasy displayed by people with schizophrenia. However, what Kanner was actually describing was a lack of imagination and a failure to develop relationships, not a withdrawal from relationships into a rich fantasy life (Rutter, 1978). This link with schizophrenia also led to a trend of using the term autism interchangeably with both childhood schizophrenia and child psychosis (Rutter, 1978).

Kanner later noted that autism could arise after an apparently normal development in the first 1 to 2 years of life and decided to reduce the list of essential symptoms to just two, "extreme aloneness" and "preoccupation with the preservation of sameness" (Eisenberg \& Kanner, 1956). Other researchers would add "disturbances in perception" to Kanner's original description and place emphasis on this symptom as being primary (Ornitz \& Ritvo, 1968). Research by Rutter and colleagues (as cited in Rutter, 1978) led to the present classification system of three broad groups of symptoms that were found in all children with autism and were much less frequently evinced by children with other psychiatric diagnoses. These symptom classes were described as "a profound and general failure to develop social relationships", "language retardation with impaired comprehension, echolalia and pronominal reversal", and "ritualistic or compulsive phenomena" (Rutter, 1978). The DSM-IV-TR utilizes this three-part classification system with deficits in communication, social interaction, and restricted interests or behavior as the primary groups of symptoms.

\section{Core Symptoms}

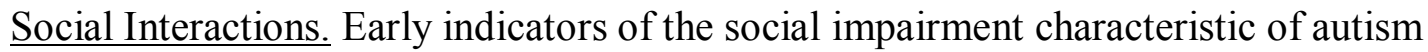
include a lack of attachment behavior, failure to bond with caretakers, not seeking comfort when hurt or upset, and a lack of or abnormal use of eye-to-eye gaze (Rutter, 1978). One area that such 
children appear to have marked difficulty with is nonverbal joint attention skills (Mundy \& Crowson, 1997). Joint attention involves looking at another person and then looking at or gesturing to an object of interest to draw that person's attention to the object. Such behavior usually occurs at around 6-9 months in a normally-developing child but is notably impaired or absent in a child with autism. Children with autism have marked difficulty with initiating as well as responding to joint attention bids (Baron-Cohen, 1989; Mundy, Sigman, Ungerer, \& Sherman, 1986). Deficits in joint attention can be seen as a precursor to many of the more apparent social disturbances that develop as the disorder progresses. Specifically, nonverbal joint attention skills may be seen as an index of symptoms listed in the DSM-IV-TR such as lack of sharing enjoyment, interests, or achievements with others as well as impairment in nonverbal behaviors (Kasari, Sigman, Mundy, \& Yirmiya, 1990).

Children with autism have widespread deficits in the orientation, recognition, and response to social stimuli. These deficits are evident in comparison with both children with Down's syndrome and developmentally-matched children without ID (Dawson, Meltzoff, Osterling, Rinaldi, \& Brown, 1998). Such children also show marked impairments in responding to an adult asking for help and expressing distress (Bacon, Fein, Morris, Waterhouse, \& Allen, 1998; Sigman, Kasari, Kwon, \& Yirmiya, 1992). An impairment in social referencing (i.e., looking to an adult for social cues in response to unfamiliar stimuli) is also evident in children with ASD (Bacon et al., 1998). These studies highlight impairments both in the recognition of and response to the emotions of others. For example, in one experiment, the children with ASD continued to play with their toys when an adult pretended to be hurt (Sigman et al., 1992). Impairments in recognizing and responding to social stimuli are likely to manifest themselves in play situations, which is often the primary vehicle for social interaction in 
children. This phenomenon is often most striking in pretend play (Jarrold, Boucher, \& Smith, 1993). Specifically, the play interactions of such children with other children are shorter and initiated less by a child with ASD than those of children with ID only (Jackson et al., 1998). However, deficits in peer-related social behaviors (e.g., being in close proximity to other children, receiving social bids, and focusing on other children) in children with ASD are evident in all social activities, not just play (McGee, Feldman, \& Morrier, 1997). Children with autism generally respond more positively to adults than to children. This factor may be the result of interactions with adults centering on need fulfillment and not being purely social, as is the case when interacting with other children (Jackson et al., 2003).

Another area of social interaction that proves to be very difficult for individuals with autism is "reading" other people. Something that develops naturally without conscious effort in people without the condition, those with autism have marked difficulties in picking up on other people's social and emotional cues and gleaning others' feelings and beliefs from conversation (Gilberg, 1990; Rutter, 1983). These deficits may be specific to autism and not generalizable to those with ID. For example, children with ASD have been shown to have greater difficulty in discriminating social and emotional cues than children with ID of the same age (Hobson, 1986a, 1986b). Individuals with autism also demonstrate impairment in expressing the appropriate emotion required for a given situation (Cohen, Paul, \& Volkmar, 1986).

As originally noted by Kanner, children with autism will oftentimes show a stronger attachment to objects than to people (Cohen et al., 1986). Such avoidance of social stimuli has been demonstrated even in infants with autism - children in one study spent significantly less time looking at people and significantly more time looking at objects compared to both developmentally delayed and normal infants (Swettenham et al., 1998). Results such as this 
present evidence for the existence of social impairment at very young ages in autistic children. Other researchers have argued that this impairment results from a general deficit in orienting ability that is more pronounced for social stimuli (Dawson et al., 1998).

It's also been suggested that these social deficits stem from a cognitive defect in dealing with social and emotional cues (Rutter, 1983). This view holds that only those areas of social interaction that require an individual to recognize and understand the emotions of other people are impaired (Braverman, Fein, Lucci, \& Waterhouse, 1989), whereas other social capacities that only require perception of the observable world (e.g., face recognition) do not become impaired (Baron-Cohen, 1988; Gillberg, 1990). Children with ASD do, however, have difficulty in tasks of affect matching as well as in other matching tasks such as faces and objects (Braverman et al., 1989; Hobson, 1986a, 1986b). Impairment in socialization may also stem from neurological abnormalities associated with the disorder (Mundy \& Sigman, 1989).

Communication. A deficit in communication is the second main diagnostic category for ASD. For a diagnosis of autism, the DSM-IV-TR requires at least one of the following impairments to be present: 1) delay in the development of or absence of spoken language; 2) in individuals with adequate speech, marked impairment in the ability to initiate or sustain a conversation with others; 3) stereotyped and repetitive or idiosyncratic language; and, 4) lack of varied, spontaneous make-believe play or social imitative play appropriate to the developmental level (APA, 2000). The development of speech is usually absent or delayed in children with autism, and it's been estimated that about 50\% never gain functional speech (Rutter, 1978). In those who do develop speech, echolalia or other abnormalities such as pronoun reversal (e.g., saying, "You want a snack" instead of "I want a snack") are often present (Rutter, 1978). People with autism have particular difficulties in both the production (Baltaxe, 1977; Baltaxe \& 
D'Angiola, 1992; Stone \& Caro-Martinez, 1990; Tager-Flusberg \& Anderson, 1991) and comprehension of pragmatic language (Paul \& Cohen, 1985; Hewitt, 1998). Specifically, appropriate conversation skills are particularly limited in this population. Individuals with ASD have great difficulty in responding to conversational questions that are either lengthy and/or requiring the person to draw inferences in order to respond (Hewitt, 1998). In conversation, people with autism oftentimes give the impression that they are talking at someone rather than with them and have trouble talking about anything outside the present situation (Rutter, 1978).

Restricted Behavior. Tracing back to Kanner's original definitions, this domain of autistic symptomology has frequently been characterized as an "insistence on sameness" in the literature. It has also been described as a lack of "behavioral flexibility" (Wahlberg \& Jorden, 1991). According to the DSM-IV-TR, at least one of the following must be evident for a diagnosis of autism: 1) preoccupation with one or more stereotyped and restricted patterns of interest of abnormal intensity or focus; 2) apparently inflexible adherence to specific, nonfunctional routines or rituals; 3) stereotyped and repetitive motor mannerisms; and, 4) persistent preoccupation with parts of objects. This domain describes a wide variety of stereotyped behaviors and routines. In early childhood, there are rigid and limited play patterns as evident in a usual lack of imaginative or make-believe play (Rutter, 1978). Children with ASD often have intense, nonfunctional attachments to objects or play with toys in bizarre ways such as twirling them around (Rutter, 1978). Ritualized or stereotyped behaviors (e.g., rocking, handflapping, self-injurious behavior) are also common. Finally there is a marked resistance to changes in routine and the environment. 
$\underline{\text { ASD and ID }}$

Kanner originally believed that children with autism possessed normal intelligence; he viewed their poor functioning as a consequence of their failure to develop relationships, not any underlying intellectual disability. Children with autism's oftentimes good rote memory, serious countenance, and lack of physical deformities helped perpetuate this view (Rutter, 1978).

However, after it was determined that IQ scores held the same meaning for children with ASD as they did for all other children, the current view that the two conditions (i.e., ASD and ID) can coexist was adopted (Rutter, 1978). Researchers have since concluded that most individuals with ASD are in fact intellectually disabled, and many do not develop functional expressive language (Mesibov, Adams, \& Schopler, 2000; Volkmar, Klin, \& Cohen, 1997).

However, there has been much debate over what percentage of persons with ASD actually have ID (Edelson, 2006). As stated in the DSM-IV-TR: "In most cases, there is an associated diagnosis of Mental Retardation, which can range from mild to profound." (APA, 2000, p. 71). Approximately $75 \%$ of those with ASD are also believed to be intellectually disabled, and ASDs can occur with equal frequency across different levels of ID (APA, 2000; Joseph, Tager-Flusberg, \& Lord, 2002). Other researchers disagree with this number, and the percentage of those with both conditions is currently reported to be between $67 \%$ and $90 \%$ (Edelson, 2006). Hermelin and O'Connor (1970) systematically analyzed the intellectual differences between children with autism and matched children with ID only. These researchers found that those with ASD made less use of meaning in their memory processes, demonstrated an impaired use of concepts, and were limited in their coding and categorizing abilities. This indicates that children with ASD have a specific cognitive deficit that involves language and central coding processes that children with ID alone do not (Rutter, 1983). 
Furthermore, persons with ID display relatively even delays across multiple areas of development while those with ASD usually evince uneven development with deviations in a few specific areas (e.g., expressive and receptive communication; Cohen, et al., 1986). Some researchers have described a specific IQ profile on Wechsler intelligence tests for those with ASD. Specifically, these individuals demonstrate higher Performance IQ than Verbal IQ, with peak subtest score on Block Design (Happé, 1994; Lincoln, Allen, \& Kilman, 1995). In children with ASD who possess functional language and function intellectually in the range of mild ID or above, this discrepancy between verbal and nonverbal abilities may lessen with age (Joseph et al., 2002). A greater discrepancy between these two areas has also been shown to be related to degree of social impairment. Specifically, those people with a greater discrepancy between verbal and nonverbal abilities evince greater social impairment, independent of verbal ability (Joseph et al., 2002). However, these results should be interpreted cautiously since the use of traditional measures of intelligence with autistic individuals may be in itself problematic due to the language, attention, and processing difficulties associated with the disorder (Edelson, 2006). Degree of social impairment has also been demonstrated to be positively correlated with intellectual ability (Wing \& Gould, 1979). Individuals with severe and profound ID are therefore more likely to evince greater social skills deficits than those with mild or moderate impairment. Different levels of intellectual disability are also likely to produce distinctive patterns of deficits in social skills. Children with low IQ and ASD demonstrate more severe social impairment and are more likely to exhibit inappropriate social behavior (e.g., stereotypies, self injury) than ASD children with higher IQs (Rutter, 1983). 


\section{Classification}

Autistic Disorder. According to DSM-IV-TR criteria, Autistic Disorder is defined by (1) qualitative impairment in social interaction, (2) qualitative impairment in communication, and (3) restricted, repetitive, and stereotyped patters of behavior, interest, and activities (APA, 2000). The DSM-III had regarded these three categories of symptoms as of equal importance in defining autism, whereas the introduction of the DSM-IV-TR has suggested a shift towards viewing social impairment as the most critical feature of autism (Charman et al., 1997; Stella, Mundy, \& Tuchman, 1999). For example, to make a diagnosis of autism, two items in the social impairment domain are required, whereas only one is needed in the communication and restricted behavior domains. These social deficits are listed as: 1) impairment in multiple nonverbal behaviors; 2) failure to develop peer relationships appropriate to developmental level; 3) a lack of spontaneous seeking to share enjoyment with others; and, 4) a lack of social and emotional reciprocity (APA, 2000). Altogether, a total of at least 6 deficits across the three domains need to be displayed prior to the age of 36 months.

Asperger's Syndrome. The existence of AS adds validity to the concept of autism spectrum disorders (Gilberg, 1990). Autism spectrum disorders can be viewed as a continuum of functioning with autism at the lower functioning end, Asperger's at the higher functioning end, and PDD-NOS occupying the middle. However, there is also a debate as to whether or not AS is a separate condition from high-functioning autism (HFA; Schopler, Mesibov, \& Kunce, 1998); HFA is simply autism without intellectual disability (Khouzam, El-Gabalawi, Piruani, \& Priest, 2004). AS was first documented, independently and only one year later than Kanner's original description of autism, by Hans Asperger in 1944. As with autism, individuals with Asperger's syndrome display impairment in communication and socialization as well as restricted interests 
and repetitive behaviors. However, there is no delay/absence of language acquisition or intellectual disability associated with Asperger's; symptoms are also not evident until 3 years or later. Language development may even be accelerated in Asperger's syndrome with early acquisition of language and hyperlexia commonly occurring. Problems with coordination and visuo-spatial impairment have also been associated with the condition (Gillberg, 1989).

PDD-NOS. Nowhere in the literature is there any one explicit definition for PDD-NOS, which in most cases is defined by what it is not, that is, autism (Mayes, Volkmar, Hooks, \& Cicchetti, 1993). In fact, even though PDD-NOS is probably much more prevalent than true autism, it has been studied much less (Mayes et al., 1993). Although, at present, there are no systematic or reliable methods of diagnosing PDD-NOS (Towbin, 1997), it is the most commonly diagnosed ASD (Matson \& Boisjoli, 2007). Typically, the label PDD-NOS is used when other ASD diagnoses do not fit (Tidmarsh \& Volkmar, 2003) or in reference to less severe forms of autism. Children with PDD-NOS have also been shown to display better communicative and cognitive skills than those with autism (Cohen et al., 1986), as well as less severe disturbances in social relatedness (Mayes et al., 1993). Key elements of the definition as described in the DSM-IV-TR include impaired development in verbal and nonverbal communication, interests, activities, and/or with the presence of stereotypies. Additionally, criteria for other ASD, Schizophrenia, Schizotypal Personality Disorder, or Avoidant Personality Disorder cannot be met (APA, 2000). Therefore, PDD-NOS definitions are as much about what the disorder is not versus the symptoms that define the condition, although some research provides differences in symptoms between PDD-NOS and autism (Mayes et al., 1993; Njardvik, Matson, \& Cherry, 1999). 


\section{Defining Social Skills}

McFall and Marston (1970) conducted one of the first studies to specifically deal with social skills. The goal of this study was to help shy male college students develop "appropriate assertiveness" as a means of getting dates. The strategies described in this paper were later modified and applied to clinical populations, specifically adults with schizophrenia and major depression (Hersen \& Bellack, 1976). Not long after, these applications were extended to persons with intellectual disabilities (Matson, Kazdin, \& Esveldt-Dawson, 1980; Matson \& Senatore, 1981) and those with visual impairments (Matson, Heinze, Helsel, Kapperman, \& Rotatori, 1986; Van Hasselt, Hersen, \& Kazdin, 1985).

Because the term social skills is used to refer to such a large and heterogeneous area of study, no consensus has been reached on any agreed-upon definitions that apply to all interpersonal situations. Simply stated, social skills are specific, identifiable skills that result in socially competent behavior (Hops, 1983). Such skills enable effective social interaction with others (Gresham \& Elliott, 1984). Many definitions also describe social skills in terms of an interaction between an individual and his or her environment. For example, Argyris $(1965,1968$, 1969) put social skills in terms of behaviors that enhance a person's contribution to the larger network of which he or she is a part. Social skills not only enable an individual to adjust and respond appropriately to environmental cues but can also provide the person with a means of coping in stress-inducing situations and avoiding interpersonal conflict (Matson, 1994). Social interactions and relationships with other people are necessary for healthy emotional functioning and psychological adjustment, and social skills are the building blocks that enable a person to obtain these things (Guralnick, 1986). Social skills also allow an individual the opportunity to express both positive and negative feelings in interpersonal situations without losing social 
reinforcement (Hersen \& Bellack, 1977; Libet \& Lewinsohn, 1973). Christoff and Kelly (1983) define social skillfulness functionally, in terms of effectiveness - in any situation, an action can be termed skillful if it effectively coordinates appropriate verbal and nonverbal behaviors to in turn elicit a desired response from the environment. Although, the majority of these definitions were not formulated with specific regard to those with ID, their common themes can be applied to all populations.

\section{ID and Social Skills}

The current diagnostic criteria for ID as outlined by the DSM-IV-TR include both "significantly subaverage intellectual functioning" and "concurrent deficits or impairments in adaptive functioning" (APA, 2000, p. 39). It is well known then, that individuals with ID evince greater deficits in socials skills than the general population. Social skills deficits in such persons can be traced back to a lack of opportunities, knowledge, practice, feedback, and/or reinforcement, as well as being the result of other problems (Elliott \& Gresham, 1993). In many cases, especially with regard to severely impaired individuals, adaptive behavior proves easier to determine and contains much more heuristic value in describing the person's abilities/level of functioning (Kraijer, 2000).

Inappropriate social behaviors displayed by persons with ID can be classified as either social deficits (e.g., failure to make eye contact when interacting with others) or social excesses (e.g., constantly seeking reassurance from a caregiver; Kuhn, Matson, Mayville, \& Matson, 2001). Limitations in the ability to communicate may exacerbate the social skills deficits seen with this population. Many people with severe ID are nonverbal or have problems with speech and hearing. Impairment in communication is one of the other benchmarks for ASD so there is 
naturally a lot of overlap among the two conditions. Social and communicative deficiencies are also associated with increases in challenging behaviors.

Individuals with ID often have difficulty dealing with changes in the environment, which can leave them vulnerable to a wide range of disorders (Parkes, 1975). Having a functional repertoire of social skills can provide such persons with some of the tools necessary to cope with the unpredictable flux of daily life. Therefore an increase in adaptive and social functioning is necessary to better prepare persons with ID for independent living (Matson, Carlisle, \& Bamburg, 1998). Another way to achieve increased independence is by decreasing maladaptive behaviors and psychiatric symptomology. This can also be accomplished by increasing positive social and adaptive behaviors (Helsel \& Matson, 1988; Matson \& Barrett, 1993). As a result, assessment of social skills is of utmost importance with this population.

\section{ASD and Social Skills}

Many of the initial investigations into the social impairment of autism looked at differences in adaptive skills or behavior. Social skills are one of the main components of adaptive behavior, which also includes communication and daily living skills. A review of such studies involving both children and adults with ASD follows.

\section{$\underline{\text { Studies with Children }}$}

Using the Vineland Social Maturity Scale (VSMS), which was the precursor to the Vineland Adaptive Behavior Scales (VABS), Gould (1977) conducted the first study examining the adaptive skills of intellectually disabled children with and without ASD. The ASD children in this study were described as being diagnosed with "early childhood psychosis including autism". The level of social functioning of this group was found to be significantly below that of the group with ID only. 
Multiple studies have compared the adaptive skills (including measures of communication and socialization) of children with autism to other demographic groups; however, there is comparatively little research specifically analyzing the social skills of children with ASD. Loveland and Kelley (1988), for example, found no significant difference between the adaptive skills of adolescents with autism and those with Down's syndrome of similar mental age; however the autism group was found to be significantly delayed in the acquisition of behaviors on the Communication and Socialization domains of the VABS (e.g., interpersonal relationships, play and leisure skills, sensitivity to other people). On the other hand, when compared to nonautistic, developmentally delayed children of similar age and intelligence level, children with autism were shown to exhibit greater deficits in overall, positive social behaviors (Volkmar et al., 1987; Volkmar, Carter, Sparrow, \& Cicchetti, 1993).

Rodrigue, Morgan, and Geffken (1991) compared the adaptive skills of children with autism, Down's syndrome, and normal development matched on adaptive behavior age equivalent as well as gender, race, birth order, family size, and SES. The three primary domains of the VABS (Communication, Daily Living Skills, and Socialization) were used as the measure of adaptive skills. The autism group obtained significantly lower scores on the Socialization domain than both the Down's syndrome and control groups; these latter two groups were not found to be significantly different. The autism group also obtained significantly lower scores on all three subdomains of the Socialization domain (Interpersonal Relationships, Play and Leisure Skills, and Coping Skills) indicating a pervasive deficit in social development. No significant differences were found on the Communication and Daily Living Skills domains among the three groups. The results of this study lend support to the notion that deficits in social functioning seen in ASD can not simply be attributed to developmental level. 
In another study, Mayes et al. (1993) attempted to differentiate between children with PDD-NOS, autism, and language disorders by using a list of items compiled from DSM-III-R and ICD-10 criteria for autism, the VABS, and the Autism Behavior Checklist (ABC). Seven of these items were found to significantly distinguish the autism group from the PDD-NOS group: chooses solitary activities, poor social signals, abnormal comfort seeking, lack of social usage, impaired make-believe, impaired conversation, and interest in nonfunctional aspects of objects. The autism group, therefore, evinced more difficulty in these areas than the PDD-NOS group. The first three of these items pertain directly to aspects of social functioning. In addition, the children in the PDD-NOS group were found to differ significantly from the language disorder group on 21 of the items indicating that this group has more difficulties with social relatedness and more of a need for routines and order.

Jacobson and Ackerman (1990) conducted a large-scale study of archival data comparing the adaptive skills of children (ages 5-12), adolescents (ages 13-21), and adults (ages 22-35) with ASD to matched peers with ID. Participants were matched by age, intelligence, and living situation (with family, community group homes, or institutions). A different pattern of results emerged for the children and adolescents than for the adults. The children and adolescents with ASD displayed more developed adaptive skills than their peers with ID, but the opposite trend was observed when comparing the adults - the adults with ID were found to possess better adaptive skills. However, the adaptive skills analyzed in this study referred mainly to the motoric and instrumental activities of daily living (e.g., toileting, grooming, language, quanitative skills) and not explicitly to any social skills.

It would be presumed then that the social impairments discussed above would persist into adulthood. It does appear that as individuals with ASD grow older their interest in socializing 
with others increases significantly (Mesibov, 1984). However, this is more likely to be the case with adults with moderate to mild ID. Likewise, Shattuck et al. (2007) administered the Autism Diagnostic Interview-Revised (ADI-R) to a sample of 241 adolescents and adults ages 10-52. Re-administering the ADI-R 4.5 years later, they found that there was an overall improvement in autistic symptomology over time, but that for more than half the sample, impairments in social reciprocity persisted. In addition, lack of friendships and impairment in conversational reciprocity were found to be the most prevalent deficits among the sample.

$\underline{\text { Studies with Adults }}$

Research concerning the social behavior of intellectually disabled adults with ASD is virtually nonexistent. Njardvik et al., 1999 compared the social skills profiles of intellectually disabled adults with autism, PDD-NOS, and those with ID only (no diagnosis on Axis I). Using the Matson Evaluation of Social Skills for Individuals with Severe Retardation (MESSIER) and the Socialization domain of the VABS, three main distinctions were noted: (1) the autism group evinced greater deficits in social skills on the Socialization domain of the VABS and the Positive Nonverbal and General Positive subscales of the MESSIER; (2) the PDD-NOS group evinced more adaptive social skills on the Positive Nonverbal subscale of the MESSIER than the autism group; and, (3) no significant differences were found between the PDD-NOS group and the ID only group. The sample used in this study was limited in terms of overall size $(N=36)$, degree of ID (only those with profound ID were included), unequal distribution of participants taking some form of psychotropic medication, and unequal distribution of gender across the three groups. Thus, these data must be considered quite preliminary.

These results do support the notion that social skills deficits have a positive correlation with severity of autism. The group with PDD-NOS, which can be viewed as a less severe form of 
autism, exhibited better positive nonverbal social skills than the autism group (Njardvik et al., 1999). However, it would be expected that the PDD-NOS group would then exhibit a greater social skills deficit than those without ASD, which was not the case here. It might also reasonably be inferred then, that people with Asperger's syndrome, who are usually higher functioning than people with autism, would also show less deficits in social skills than people with autism or PDD-NOS. In Asperger's syndrome there is normal to highly developed language skills so this is one area which would likely produce marked differences between these groups. This hypothesis awaits investigation.

In a similarly structured study, Matson, Mayville, Lott, Bielecki, and Logan (2003) found that adults with ID and ASD had significantly lower mean scores on all three domains of the VABS (i.e., Communication, Daily Living Skills, Socialization) and significantly higher scores on the Negative Nonverbal subscale of the MESSIER when compared to those with ID only. In terms of strictly adaptive skills (i.e., daily living skills, language, and reasoning), adults with ASD showed more deficits than those with ID only (Jacobson \& Ackerman, 1990). Individuals with ASD also exhibit higher levels of inappropriate social behaviors (Matson, StabinskyCompton, \& Sevin, 1991). Overall, the results of these studies indicate that children and adults with ASD may be in greater need of social skills training than those with ID. The specific skills addressed in such training would also most likely differ.

\section{Assessment of Social Skills}

One of the most important components in the assessment of the intellectually disabled is the identification of specific social skills deficits and excesses. Measures of social skills and adaptive behavior provide a wealth of information that can be used to obtain an overall picture of how an individual functions on a daily basis. Such measures are generally more useful with this 
population than traditional IQ measures, which are rarely accurate beyond the mild range of ID. Skill deficits identified by these measures can be targeted and trained to individuals with ID so that they can achieve more independence in their daily lives and be better prepared for living outside of residential facilities. A variety of methods are available for quantifying level of social skill, including sociometric techniques, direct observation, behavioral interviews, and ratings made by teachers, parents, and self (Lyon, Albertus, Birkinbine, \& Naibi, 1996).

\section{$\underline{\text { Rating Scales }}$}

Because of their ease of administration and interpretation, rating scales have become the most popular assessment technique for identifying social skills deficits and excesses in people with ID (Marchetti \& Campbell, 1990). The administration of rating scales to caregivers can save time and financial resources as well as provide a reliable and valid means of assessment (Matson, Mayville, \& Laud, 2003). Measures are available for children and adults and cover the entire spectrum of intellectual disability. These instruments have proven to be more objective, reliable, and efficient than other frequently used methods for assessing social skills (Marchetti \& Campbell, 1990).

MESSIER. The MESSIER is a measure designed to assess the social strengths and weaknesses in adults with severe and profound ID (Matson, 1995). The scale contains 85 items distributed across six clinically derived dimensions: Positive Verbal (e.g., apologizes for unintentional mistakes); Positive Nonverbal (e.g., smiles in response to positive statements); General Positive (e.g., responds appropriately when introduced to strangers); Negative Verbal (e.g., speech shows no emotion); Negative Nonverbal (e.g., responds to hugs with rigidity); and General Negative (e.g., has trouble waiting for needs to be met). A caregiver of the individual being assessed is asked to rate the frequency of each item using a 4-point Likert-type scale: never 
(0), rarely (1), sometimes (2), and often (3). Endorsed items can be transcribed onto a scoring profile under their respective subscales, which allows the clinician to examine relative strengths and weaknesses. This clinical profile can then be used for determining individualized treatment goals, and repeated assessment can be used for evaluating such training (Paclawskyj, Rush, Matson, \& Cherry, 1999).

The MESSIER has other uses as well. It has been shown to successfully classify level of ID at the severe and profound levels (Matson, Dixon, Matson, \& Logan, 2005). This is advantageous since standardized IQ tests are of minimal value in identifying strengths and weaknesses for treatment planning for the intellectually disabled (Matson, 1990). Adaptive behavior scales also tend to fall short in describing possible treatment goals with the severely disabled as they are geared primarily toward persons with mild or moderate ID (Matson et al., 2005). In addition, the MESSIER can also be used to differentiate individuals with ID presenting with psychopathology from those without psychopathology (Matson, Smiroldo, \& Bamburg, 1998). Finally individuals who display maladaptive behaviors (e.g., rumination, stereotypies, aggression, and self-injury) have been shown to systematically vary with regard to their MESSIER profiles based on what form of challenging behavior they exhibit (Duncan, Bamburg, Cherry, \& Buckley, 1999; Kuhn et al. 2001; Matson, Smiroldo, et al., 1998).

The MESSIER has sound psychometric properties. Reliability ratings including interrater $(r=.73)$, test-retest following a period of 2-3 weeks $(r=.86)$, and internal consistency (Alpha $=$ .94), have been shown to generally be high (Matson, LeBlanc, Weinheimer, \& Cherry, 1999). Factor analysis of the MESSIER yielded two dimensions: one factor describing positive social behaviors and another describing negative social behaviors (Paclawskyj et al., 1999). Convergent validity was demonstrated by comparing MESSIER subscales to equivalent 
subdomains from the VABS (Matson, Carlisle, et al., 1998) and with sociometric ranking (LeBlanc, Matson, Cherry, \& Bamburg, 1999). This pattern suggests that MESSIER ratings accurately reflect a person's level of social functioning with higher scores indicative of better social functioning (LeBlanc et al., 1999).

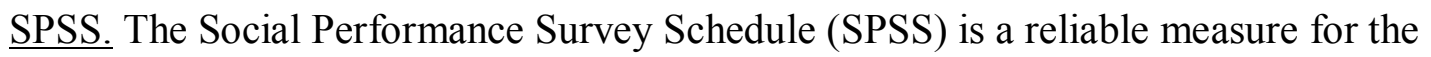
assessment of social skills in individuals with mild to moderate intellectual impairment (Matson, Helsel, Bellack, \& Senatore, 1983). The SPSS is similar to the MESSIER but its item content taps into a higher level of social functioning. It contains 57 items measuring positive and negative social behaviors Ratings are made on a 5-point Likert-type scale: not at all, a little, a fair amount, much, and very much. Typical items on the SPSS include such things as: has eye contact, shows enthusiasm for other's good fortune, interrupts others, threatens others verbally and physically, and knows how to leave people alone. Interrater reliability is adequate $(r=.57)$ with items pertaining to overt social behavior being more reliable. A factor analysis of the SPSS produced a four-factor solution with the factors being labeled Appropriate Social Skills, Poor Communication Skills, Inappropriate Assertion, and Sociopathic Behavior (Matson, Helsel, et al., 1983). A self-report form of the SPSS has also been developed containing the same items but without pronouns.

MESSY. The Matson Evaluation of Social Skills with Youngsters (MESSY) is a 64-item inventory that measures the social behaviors of children (Matson, 1989). The frequencies of items are rated on a Likert-type scale ranging from (1) not at all to (5) very much. There are two versions of the MESSY, a teacher-report form, which can also be completed by caretakers, and a self-report form. The teacher form yields two factors: Inappropriate Assertiveness/Impulsiveness (e.g., threatens people or acts like a bully) and Appropriate Social Skills (e.g., helps a friend who 
is hurt). Factor scores are considered "problematic" if they fall one standard deviation below the normative mean, while scores are considered "very problematic" if they fall two or more standard deviations below the mean. The psychometric properties of the MESSY are good and have been demonstrated across various subgroups such as visually handicapped and hearing impaired children with excellent split-half reliability (Matson, Rotatori, \& Helsel, 1983; Matson et al., 1986) and internal consistency (Matson, Macklin, \& Helsel, 1985; Matson et al., 1986). The MESSY has also been demonstrated to be effective in measuring social skills deficits in children with autism (Matson et al., 1991). For hearing impaired children, it was shown to correlate with intelligence level as well as the A-M-L Behavior Rating Scale, which is a measure of emotional behavior (Matson et al., 1985). The MESSY norms are currently in the process of being updated.

SSRS. The Social Skills Rating System (SSRS) is a norm-referenced rating scale that can be used for assessing the social functioning of children in preschool through $12^{\text {th }}$ grade (Gresham \& Elliot, 1990). There are three versions of the SSRS, one for teachers, parents, and students. The length of these forms varies (34-55 items) depending upon the person making the ratings and the grade level of the student being assessed. All responses are completed on a 3-point Likert-type scale. Ratings are made concerning the frequency of a behavior (never, sometimes, very often) and its "importance" for classroom success (not important, important, critical). The SSRS contains three main subscales: social skills (teacher, parent, and student forms), problem behaviors (teacher and parent forms), and academic competence (teacher form only).

The SSRS also includes norms for elementary students with disabilities. On average, disabled children score between one and two standard deviations below their nondisabled peers (Gresham \& Elliott, 1990). A similar discrepancy has been found with the SSRS scores of 
disabled preschoolers as well (Lyon et al., 1996). Although the SSRS has been shown to discriminate between broad groups of disabled and nondisabled students, it failed to distinguish between more specific groups such as learning disabled, mild ID, and behaviorally disordered (Bramlett, Smith, \& Edmonds, 1994; Gresham, Elliott, \& Black, 1987). However, it was found that children with ID were more likely than those with a learning disability to score within "atrisk" levels on teacher ratings of social skills and problem behaviors (Bramlett et al., 1994).

The teacher and parent forms have adequate to excellent internal consistency and testretest reliability (Demaray et al., 1995; Gresham \& Elliot, 1990). Although the student form was shown to have good internal consistency (DiPerna \& Volpe, 2005), its test-retest reliability for the social skills scale was limited (Demaray et al., 1995). In addition, interrater reliability for the teacher and student forms was low for the total score and even lower across the subscales (DiPerna \& Volpe, 2005). A moderately strong correlation was found between the total score of the SSRS teacher form and both the Socialization Domain of the VABS and the Teacher Questionnaire (Lyon et al., 1996) as well as with Walker-McConnell Scale of Social Competence and School Adjustment and the MESSY (Demaray et al., 1995). However, convergent validity of the student form has not been as encouraging (DiPerna \& Volpe, 2005).

VABS. The VABS is one of the first standardized checklists used in the assessment of social and adaptive behavior for persons with ID (Sparrow, Balla, \& Cicchetti, 1984). This measure contains norms for both ambulatory and nonambulatory adults with ID living in residential and nonresidential facilities. The VABS consists of five domains: Communication, Daily Living Skills, Socialization, Motor Skills, and Maladaptive Behavior. Items can be rated as 2 (yes, usually); 1 (sometimes or partially); 0 (no, never); N (no opportunity); or DK (don't know). Reliability coefficients for the internal consistency of the entire scale are high, averaging 
in the $.80 \mathrm{~s}$ and $.90 \mathrm{~s}$. The Socialization Domain contains 58 items that are listed in the order they should be developmentally achieved. This domain contains three subdomains: Interpersonal Relationships, Play and Leisure Skills, and Coping Skills. The Socialization domain has been shown to have high internal consistency $(r>.80)$ and substantial construct validity $(r>.70)$.

\section{Observation Techniques}

Simply observing an individual's social behavior in either naturalistic or analog conditions is another common method of assessing social skills. Naturalistic observations can occur in any setting that the person being assessed commonly spends time in and can include observations made by several raters based on pre-established target behaviors (Marchetti \& Campbell, 1990). An analog observation, on the other hand, would occur in an artificial environment with different situational variables being manipulated in order to evaluate a person's overall repertoire of social behaviors (Castles \& Glass, 1986).

\section{Role-Play}

Role-play is one of the most widely used methods of assessing social skills in children (Matson, Esveldt-Dawson, \& Kazdin, 1983). Such role-play scenarios can obviously be tailored to adults as well. Typical assessment with role-play scenes should contain situations tapping into elements of both positive (e.g., giving compliments, giving help, and sharing) and negative social interactions (e.g., response to threats or provocation from peers; Wilkins \& Matson, 2007).

Responses are typically evaluated for the presence or absence of 4-6 operationally defined target behaviors (Kazdin, Esveldt-Dawson, \& Matson, 1983; Matson, Esveldt-Dawson, et al., 1983). One advantage of role-play assessment is that the individual's behavior can be observed directly rather than inferred from the responses on checklists that were completed by a second-party. However, it has not been demonstrated convincingly that performance in such role-play scenes 
predicts how well someone actual behaves in vivo. For example, role-play performance was shown to not be consistently correlated with peer nominations, the MESSY, or a structured interview with the child being assessed (Matson, Esveldt-Dawson, et al. 1983). Other studies have found test-retest reliability and validity of role-play assessment to be low (Van Hasselt, Hersen, \& Bellack, 1981) and that positive experiences immediately preceding the assessment could radically affect performance (Kazdin et al., 1983).

In summary, there are a variety of methods available for assessing the social skills of individuals with ID. Given the ease and brevity of administration, rating scales have become the most commonly used assessment tools. Although a variety of measures are available, the MESSIER and VABS are the most researched and popular instruments for the assessment of social behavior in intellectually disabled adults. These scales have become a required component in the yearly psychological evaluations of adults with ID living in residential and institutional settings. As such, the MESSIER and Socialization domain of the VABS will be the measures employed in the present study to investigate the nature of social behavior in adults with ASD and ID. 


\section{PURPOSE}

Intellectually disabled adults with ASD represent an understudied group in that most of the research in this area has focused on children. The exact nature of social impairment in this population is not fully understood, and it is unknown whether social deficits in adults are qualitatively or quantitatively different than those exhibited by children with ASD. Although, the linguistic, social, and obsessive behavioral difficulties usually persist into adulthood, they do so in forms that are different than those exhibited as a child (Rutter, 1978). The pattern of social impairment may change over the course of development; as many autistic individuals grow older they become more socially engaged, but it is not clear if this holds for adults with ID (Cohen et al., 1986). Therefore, different assessment and diagnostic procedures may be required for adults with ASD. Because deficits in social skills seem to be given the most weight of the three core symptoms in current diagnostic systems (e.g., DSM-IV-TR), this would appear to be a good starting point for the systematic investigation into the nature of ASD in adults with ID.

Further complicating the issue, however, is the fact that ASD can be difficult to differentiate from the severest forms of ID in adults. Diagnostic procedures have become much more refined over the years and their number, use, and availability have increased dramatically. As a result, many individuals who are now adults have gone undiagnosed since these systems were not in place when they were children. Correct identification of ASD is of utmost importance because service options designed for individuals with ID may be less suitable for adults with ASD (Matson \& Nebel-Schwalm, 2007; Van Bourgondien \& Elgar, 1990).

Delineating differences in social skills profiles among these groups can be beneficial in tailoring individual service options and treatment plans (Matson, 2007). A new assessment measure, the Autism Spectrum Disorders Diagnostic Scale for Intellectually Disabled Adults (ASD-DA) has 
shown promise in making the fine distinction between intellectually disabled adults with and without ID (Matson, Wilkins, \& González, 2007).

The purpose of this study was to explore the nature of social skills in adults with ASD (autism and PDD-NOS) and ID by comparing them to people with ID only. A one-way multivariate analysis of variance (MANOVA) was conducted to compare these groups on MESSIER subscales and the Socialization domain of the VABS. It was hypothesized that there would be significant differences between the three groups on these seven dependent variables. The autism group was expected to show more deficits and fewer strengths in social skills, as exhibited by higher scores on the negative subscales of the MESSIER and lower scores on the positive subscales of the MESSIER and Socialization domain of the VABS. Individuals with PDD-NOS were expected to exhibit less social impairment than the autism group but more impairment than the controls. 


\section{METHOD}

\section{Participants}

The initial sample for this study consisted of 333 intellectually disabled adults. Based on ASD-DA scores, participants were placed into one of three groups: autism $(n=72)$, PDD-NOS $(n=142)$, or control (no Axis I diagnosis; $n=119)$. However, because there was a significant difference between groups on level of ID, groups were matched on this variable in order to prevent it from confounding the results. Groups were also matched as closely as possible on verbal ability (nonverbal or verbal), age, and gender. Because most of the dependent measures assess verbal social behaviors, it was also important to eliminate verbal ability as another possible confound. Not all participants were able to be matched on this variable, but there was not a significant difference between groups $(p=.44)$. After matching, there were 72 participants in each group, 64 of whom were diagnosed with profound ID, 4 with severe ID, and 4 with ID, severity unspecified. There were 123 males and 93 females in the sample ranging in age from 16 to 81 years $(M=49.98, S D=11.59)$. Demographic information for the three groups is presented in Table 1.

Table 1. Demographic characteristics of the sample.

\begin{tabular}{lccc}
\hline & $\begin{array}{c}\text { Autism } \\
(n=72)\end{array}$ & $\begin{array}{c}\text { PDD-NOS } \\
(n=72)\end{array}$ & $\begin{array}{c}\text { Control } \\
(n=72)\end{array}$ \\
\hline Age (in years) & & & \\
$\quad$ Mean & 49.49 & 49.22 & 48.24 \\
SD & 11.40 & 10.77 & 12.65 \\
$\quad$ Range & $18.0-81.0$ & $16.0-74.0$ & $27.0-80.0$ \\
Gender (\% males) & 58.3 & 54.2 & 58.3 \\
Ethnicity (\% Caucasian) & 76.4 & 86.1 & 63.9 \\
Verbal Ability (\% verbal) & 25.0 & 30.6 & 34.7 \\
Level of ID & & & \\
$\quad$ Profound & 64 & 64 & 64 \\
$\quad$ Severe & 4 & 4 & 4 \\
$\quad$ Unspecified & 4 & 4 & 4 \\
\hline
\end{tabular}


All participants were residents of one of two developmental centers in central or south Louisiana, which vary in size from 350 to 550 residents. Most of the residents at these centers function within the profound range of ID, and the sample appears to accurately represent this population. Intellectual disability is one of the main requirements for admission to these developmental centers and is re-assessed every 5 years by a master's level psychologist using the Stanford-Binet Intelligence Scales. Those in the ASD group also presented with a range of comorbid Axis I diagnoses including Anxiety Disorder, Depressive Disorder, Pica, and Stereotypic Movement Disorder.

\section{Measures}

\section{$\underline{\text { ASD-DA }}$}

The Autism Spectrum Disorders-Diagnostic Scale for Intellectually Disabled Adults (ASD-DA) contains 31 items that have been demonstrated to be effective at differentiating intellectually disabled adults with ASD from those with ID only (Matson, Wilkins et al., 2007). The ASD-DA has adequate interrater and test-retest reliabilities. Internal consistency was excellent (Cronbach's alpha $=.94)$, and factor analysis produced a three factor solution that mirrors the three classes of core symptoms outlined in the DSM-IV-TR (i.e., impairment in socialization, communication, and restricted behavior). Informants are asked to rate how different the individual being assessed is compared to other people of the same age living in the community. Items are scored as either 0 (not different, no impairment) or 1 (some difference, some impairment). Sample items include: use of language to communicate; ability to make and keep friends; reads nonverbal cues (body language) of other people; and response to normal, everyday lights (e.g., streetlights, etc.). The convergent validity of the ASD-DA was demonstrated by high correlations with DSM-IV-TR and ICD-10 criteria for autism, total 
MESSIER score, and the Socialization domain of the VABS, while divergent validity was demonstrated by a near zero correlation with a measure of general psychopathology, the Diagnostic Assessment for the Severely Handicapped II (Matson, Wilkins, Boisjoli, and Smith, in press).

Cut-off scores for differentiating between ASD and no ASD and between autism and PDD-NOS have also been established (Matson, Boisjoli, González, Smith, \& Wilkins, 2007). A total score of 19 or greater was determined to be indicative of ASD for adults with ID, while scores of 11 on Factor I (social impairment) and 8 on Factor III (restricted behavior) were established as cut-offs for distinguishing between autism and PDD-NOS. In this initial study, no cut-off score for Factor II could effectively differentiate between those two ASD. It was noted that this factor, which pertains to communication, may have limited utility in making this distinction, as the majority of individuals in the sample had severe and profound ID and thus, limited verbal communication skills.

\section{Assessment Procedures}

A Ph.D. level student in clinical psychology with at least one year of work (20 hours a week) in the developmental center where the assessments were conducted administered the measures via clinical interview of direct care staff. Items from the ASD-DA and MESSIER were read to the staff member. The Socialization domain of the VABS was obtained from each participant's most recent yearly psychological evaluation.

\section{Power Analysis}

In order to determine if a sample size of 216 participants would provide sufficient power for the intended analyses, an a priori power analysis was conducted. GPower, a statistical computer program was used for this analysis. Following the instructions for MANOVA outlined 
in an online tutorial for GPower (Buchner, Erdfelder, \& Faul, 1997) and setting alpha at .05 with a medium effect size (Cohen, 1965), the power was determined to be 1.00 . A power value of .80 is suggested for the social sciences (Buchner et al., 1997), so it was determined that there was sufficient power to conduct the MANOVA. 


\section{RESULTS}

Analyses were conducted to determine the nature of the differences between the three groups on the MESSIER and the Socialization domain of the VABS. First, a 3 x 7 MANOVA was conducted with diagnostic group (autism, PDD-NOS, or control) as the independent variable. MANOVA was used as the primary statistical procedure to protect against inflation of alpha associated with conducting multiple one-way analyses of variance (ANOVAs; Tabachnick \& Fidell, 2001). There were seven dependent variables: the six MESSIER subscales and the Socialization domain of the VABS. Significant differences were found between the three groups on the dependent measures, Wilks's $\Lambda=.65, F(14,414)=7.02, p<.001$. The multivariate $\eta^{2}$ based on Wilks's $\Lambda$, which is an indicator of effect size, was moderately strong at .19. Table 2 displays the means and standard deviations of the dependent variables for each group.

Table 2. Means and standard deviations on the dependent variables for the three groups.

\begin{tabular}{lccc}
\hline & Autism & PDD-NOS & Control \\
Measure & $M(S D)$ & $M(S D)$ & $M(S D)$ \\
\hline MESS Pos. Verbal & $3.19(5.57)$ & $5.28(7.39)$ & $8.78(10.16)^{\mathrm{a}, \mathrm{d}}$ \\
MESS Pos. Nonverbal & $14.37(8.77)$ & $18.38(9.40)^{\mathrm{c}}$ & $24.56(10.16)^{\mathrm{a}, \mathrm{b}}$ \\
MESS Gen. Positive & $18.65(14.04)$ & $24.33(15.77)$ & $37.85(16.97)^{\mathrm{a}, \mathrm{b}}$ \\
MESS Neg. Verbal & $3.19(3.63)$ & $4.33(4.95)$ & $3.67(4.32)$ \\
MESS Neg. & & & \\
$\quad$ Nonverbal & $13.81(6.78)$ & $13.07(6.82)$ & $8.64(6.64)^{\mathrm{a}, \mathrm{b}}$ \\
MESS Gen. Negative & $8.10(6.22)$ & $9.60(7.07)$ & $7.33(6.72)$ \\
VABS Socialization & $14.72(18.62)$ & $16.33(17.10)$ & $21.46(19.36)$ \\
\hline
\end{tabular}

${ }^{\mathrm{a}}$ Significantly different from Autism group $(p<.001)$

${ }^{\mathrm{b}}$ Significantly different from PDD-NOS group $(p<.001)$

${ }^{\mathrm{c}}$ Significantly different from Autism group $(p<.05)$

${ }^{\mathrm{d}}$ Significantly different from PDD-NOS group $(p<.05)$

Seven ANOVAs were conducted (one for each dependent variable) as follow-up tests to the significant MANOVA. Using the Bonferroni method, each ANOVA was tested at the .007 level. The ANOVAs for the Positive Verbal subscale of the $\operatorname{MESSIER}(F[2,213]=9.11, p<$ $\left..001, \eta^{2}=.08\right)$, Positive Nonverbal subscale of the $\operatorname{MESSIER~}\left(F[2,213]=21.20, p<.001, \eta^{2}=\right.$ 
$.17)$, General Positive Subscale of the MESSIER $\left(F[2,213]=28.62, p<.001, \eta^{2}=.21\right)$, and the Negative Nonverbal subscale of the MESSIER $\left(F[2,213]=12.36, p<.001, \eta^{2}=.10\right)$ were significant. However, the ANOVAs for the Negative Verbal subscale of the MESSIER ( $F[2$, $\left.213]=1.25, p=.29, \eta^{2}=.01\right)$, General Negative subscale of the MESSIER $(F[2,213]=2.14, p$ $\left.=.12, \eta^{2}=.02\right)$, and the Socialization domain of the $\operatorname{VABS}\left(F[2,213]=2.64, p=.07, \eta^{2}=.02\right)$ were not significant.

Post-hoc pairwise comparisons were conducted for the four dependent measures with significant ANOVAs in order to determine which groups exhibited the most impairment in social behavior. Each pairwise comparison was tested at the .007 divided by 3 or .002 level. The autism group scored significantly lower than controls on the Positive Verbal subscale of the MESSIER, the Positive Nonverbal subscale of the MESSIER, and the General Positive subscale of the MESSIER. Compared to controls, individuals with autism also scored significantly higher on the Negative Nonverbal subscale of the MESSIER. In addition, the difference between the autism and PDD-NOS groups on the Positive Nonverbal subscale of the MESSIER was just shy of clinical significance $(p=.04)$ with individuals with autism scoring lower on this measure (see Table 2). Compared to controls, the PDD-NOS group scored significantly lower on the Positive Nonverbal subscale of the MESSIER and the General Positive subscale of the MESSIER and significantly higher on the Negative Nonverbal subscale of the MESSIER. The difference between the PDD-NOS and control groups on the Positive Verbal subscale of the MESSIER was just shy of clinical significance $(p=.03)$ with individuals in the PDD-NOS group scoring lower than controls (see Table 2). 


\section{DISCUSSION}

Intellectually disabled adults with autism and PDD-NOS do evince different patterns of social impairment than adults with ID only. As expected, this pattern was in the direction of individuals with autism showing the greatest deficits followed by those with PDD-NOS and then controls. These deficits were most evident in the area of positive social skills, both verbal and nonverbal, and the presence of negative nonverbal social behaviors (e.g., isolates self). There was a larger spread between the ASD groups (autism and PDD-NOS) and controls than between the ASD groups themselves. A similar pattern has emerged in recent research with this population, with impairments in social interaction being the most important factor in differentiating both autism and PDD-NOS from controls (Matson, Wilkins, \& Ancona, in press; Matson, Wilkins, Smith, \& Ancona, in press). Taken together, this research indicates that symptoms of social impairment persist into adulthood and remain distinct. On this note, it would be interesting to conduct a longitudinal study to see if these symptoms remain qualitatively or quantitatively similar or fluctuate from childhood to adulthood for persons with ASD and ID.

There were no differences among the groups on the General Negative and Negative Verbal domains of the MESSIER and the Socialization domain of the VABS. Therefore, quantitative differences in social behavior for this population appear to be more evident in a lack of positive social skills rather than the presence of more overt negative social behaviors. Although, the Socialization domain of the VABS describes mostly positive social behaviors, it is not entirely unsurprising that the present analysis yielded no significant differences on this measure. The VABS was not designed for adults with ID and is simply not sensitive enough to detect differences between groups within this population, as the scores were quite truncated. It addition, the VABS was completed at a different time than the other measures with a potentially 
different informant; therefore, interrater disagreement could have also contributed to the lack of significance. This finding is in line with other recent studies conducted with this population (Matson, Wilkins, \& Ancona, in press; Matson, Wilkins, Smith, et al., in press).

Similarly, as the majority of individuals in this study were nonverbal, there may not have been sufficient variability with respect to scores on the Negative Verbal domain of the MESSIER. In fact, mean scores for this domain were the lowest across all six MESSIER subscales. Although some of these items pertain to repetitive or disruptive vocalizations, many items are related to deficits in conversational skills or self-expression (e.g., complains often, makes negative statements about self), which are less likely to be exhibited by profoundly disabled individuals. In fact, these items were among the least-endorsed items for those with profound ID in the normative sample of the MESSIER (Matson, 1995).

There were no significant differences on any of the dependent variables between those in the autism and PDD-NOS groups. However, when compared to controls, the autism group had significantly different scores on four of the dependent measures while the PDD-NOS group had only three. In addition, differences in mean scores between these two groups were just shy of clinical significance on the Positive Nonverbal subscale of the MESSIER. Although these differences are subtle, it indicates that there are some differences in social behavior between intellectually disabled adults with autism and PDD-NOS. It should also be noted that a more conservative approach was taken for the post hoc analyses, and the mean difference on this variable was significant at the $p<.05$ level. However, it is likely that more significant discrepancies exist between these two groups in the area of repetitive or stereotyped behaviors. This is the other symptom domain used in differentiating the groups on the ASD-DA (Matson, Boisjoli, et al., 2007). 
A more complete picture emerges with respect to differences between the autism and PDD-NOS groups when examining individual items from the significant MESSIER subscales (i.e., Positive Verbal, Positive Nonverbal, General Positive, and Negative Nonverbal). The percent endorsed for each group on some of these items is presented in Table 3. Substantial differences can be seen between those with autism and PDD-NOS on all four of these measures with a trend in the direction of individuals with autism evincing greater deficits in positive social skills as well as exhibiting more nonverbal negative social behaviors. A similar trend is apparent for those with PDD-NOS when compared to controls. As mentioned above, it is likely that impairment in the domain of restricted behavior significantly differentiates intellectually disabled adults with autism from those with PDD-NOS. One item that is particularly illuminating in this respect, then, is "exhibits peculiar or odd mannerisms when in public". This item which is likely reflective of stereotypical or ritualistic behaviors was endorsed for $65.6 \%$ of the autism group compared to $38.9 \%$ of the PDD-NOS group.

Table 3. Percent endorsed on selected items from MESSIER subscales found to significantly differ between groups.

\begin{tabular}{lccc}
\hline Item & Group & \\
\hline Positive Verbal & Autism & PDD-NOS & Control \\
\hline $\begin{array}{l}\text { 29. Attempts to communicate using words or } \\
\quad \text { sounds. }\end{array}$ & 28.2 & 50.0 & 63.9 \\
$\begin{array}{l}\text { 55. Says "goodbye" when leaving a room. } \\
\text { Positive Nonverbal }\end{array}$ & 4.2 & 16.7 & 31.9 \\
9. Extends hand toward familiar people. & 48.6 & 58.3 & 72.2 \\
15. Smiles in response to positive statements. & 59.7 & 73.6 & 80.6 \\
General Positive & & & \\
13. Shows interest in the activities of other people. & 37.5 & 51.4 & 69.4 \\
20. Has a friend. & 30.6 & 44.4 & 76.4 \\
22. Shows a preference for certain friends over & & & \\
$\quad$ others. & 15.3 & 36.1 & 61.1 \\
Negative Nonverbal & & & \\
51. Avoids eye contact. & 66.7 & 56.9 & 28.2 \\
67. Exhibits peculiar or odd mannerisms in public. & 65.6 & 38.9 & 20.8 \\
82. Seems unaware of what is going on around him/her. & 75.0 & 69.8 & 51.4 \\
\hline
\end{tabular}


The only other study to examine specific patterns of social behavior in intellectually disabled adults with ASD was conducted by Njardvik and colleagues (1999). The main differences in the results of that study and the present analysis are as follows. First, in the Njardvik study, no differences were found between the PDD-NOS group and the ID group, whereas in the present analysis, the PDD-NOS group showed significant deficits on three of the outcome measures. Second, the autism group in the present study displayed significant deficits on more measures (four as opposed to three in the Njardvik paper). Finally, Njardvik et al.'s (1999) analysis yielded a significant difference on the Socialization domain of the VABS between the autism group and controls, which was not the case in the present paper. The results converged in several ways as well. In both papers, the Positive Nonverbal subscale of the MESSIER was the only variable able to differentiate the autism and PDD-NOS groups. Second, in both studies, the autism group scored significantly lower on the Positive Nonverbal and General Positive domains of the MESSIER when compared with those with ID only.

However, as mentioned above, the study by Njardvik et al. (1999) is best considered preliminary, and the present research extends that study in several important ways. First a much larger sample size was utilized (216 participants compared to 36). Second, group assignment was made based on ASD-DA scores. In Njardvik et al. (1999), group assignment was made based on scores on the Childhood Autism Rating Scale (CARS). As the name implies, this scale is used to diagnose ASD in children, and its utility for diagnosing adults is therefore questionable. Also, subscales on the CARS do not correspond to DSM-IV-TR criteria as it was created before this edition of the DSM was published. As a result, the much larger sample size and more rigorous group assignment has allowed for a more fine-grained analysis of social skills in this ASD population. 
Results lend evidence to the notion that autism and PDD-NOS are disorders on the same continuum, and that this spectrum is relevant for adults with ID. Although, significant differences were not obtained between the autistic and PDD-NOS groups on these global measures of social behavior, the item analysis here and other research has demonstrated that specific items pertaining to social skills deficits and excesses can differentiate the groups (Matson, Boisjoli, et al., 2007). As such, the findings of the present study also lend credibility to the utility of the ASD-DA in making the fine distinction among autism, PDD-NOS, and ID alone. There is significant symptom overlap with these groups, especially at the severe and profound level of ID, and until recently, there was very little systematic research aimed at delineating differences in symptom profiles for adults.

One potential application of these results would be to inform treatment plans of intellectually disabled adults with autism or PDD-NOS. Based on the present results, remediation of social skills excesses and deficits would not be different for those with autism or PDD-NOS within this population of institutionalized adults with ID. However, treatment plans would be qualitatively different for those with ASD as opposed to individuals with ID only. For those with ASD, programming could target the training of specific skills on the three positive subscales of the MESSIER. In addition, the treatment plan could also outline strategies for decreasing negative social behaviors on the Negative Nonverbal domain.

However, the present study is not without its own limitations - namely the generalization of the results to other samples. The majority of the sample here consisted of individuals functioning within the profound range of ID so it remains unclear if a different picture would emerge for those with mild to moderate ID. On the other hand, the makeup of the sample could also be considered a strength as there is considerable symptom overlap between ASD and 
profound ID. Impairment in social behavior becomes more pronounced as level of ID becomes more severe (Wing \& Gould, 1977), and the incidence of challenging and/or repetitive behaviors (e.g., stereotypies, self-injury) also increases, which can cloud the overall diagnostic picture (McClintock, Hall, \& Oliver, 2003; Rutter, 1983). Therefore, differences in social impairment may be more subtle in those with mild to moderate ID. One other potential research question could be investigating if there are differences in social skills between those with Asperger's syndrome or HFA and those with ASD and mild ID.

Along the same lines, the individuals of the sample were residents of a developmental center, and many had lived in such a setting for most of their lives. As such, there are different levels of social demands required of someone living in a group home as opposed to living in a developmental center. For such a study, the SPSS would be more appropriate as a dependent measure. In addition, it is likely that significant differences would appear on the Socialization domain of the VABS and items pertaining to negative, verbal social behaviors on the SPSS because the range of social behavior exhibited by this group would be expanded, not to mention the likelihood that the majority of such individuals would be able to express themselves verbally.

Finally, since the autism group also presented with a range of other Axis I mental health conditions, future studies should tease out the differences between those with ASD and those with psychopathology since other Axis I conditions may contribute to either the social skills deficits (e.g., Schizophrenia) or diagnosis of ASD (e.g., Stereotypic Movement Disorder). For example in a comparison of adaptive and social behavior, Matson, Mayville, Lott, et al. (2003) found that intellectually disabled adults with a psychotic disorder evinced significantly higher scores on the Positive Verbal subscale of the MESSIER and all three primary domains of the VABS (i.e., Communication, Daily Living Skills, and Socialization) as well as significantly 
lower scores on the Negative Nonverbal subscale of the MESSIER. However, that study was also limited by a small sample size $(N=36)$. Additionally, the diagnoses in the psychosis group were not specified and neither was the method of diagnosing ASD.

In conclusion, the purpose of this study was to investigate the differences in social behavior between intellectually disabled adults with autism, PDD-NOS, and no Axis I diagnosis. The pattern of deficits in positive social skills, both nonverbal and verbal, coupled with the presence of negative nonverbal social behaviors as differentiating those with autism from controls is consistent with previous research and may be useful for specific assessment and treatment planning. Remediation of social skill deficits can help decrease the incidence of challenging behaviors and ultimately facilitate the move of individuals from institutions into less restrictive placements in the community. 


\section{REFERENCES}

American Psychiatric Association. (2000). Diagnostic and statistical manual of mental disorders ( $4^{\text {th }}$ ed., Text Revision). Washington, DC: Author.

Argyris, C. (1965). Explorations in interpersonal competence - I. Journal of Applied Behavioral Science, 1, 58-63.

Argyris, C. (1968). Conditions for competence acquisition and therapy. Journal of Applied Behavioral Science, 4, 147-177.

Argyris, C. (1969). The incompleteness of social-psychological theory: Examples from small group cognitive consistency and attribution research. American Psychologist, 24, 893908.

Asperger, H. (1944). 'Die autistischen psycopathen im kindersalter.' Archives für Psychiatrie und Neruenkrankheiten, 117, 76-136.

Bacon, A.L., Fein, D., Morris, R., Waterhouse, L., \& Allen, D. (1998). The responses of children with autism to the distress of others. Journal of Autism and Developmental Disorders, 28 , 129-142.

Baltaxe, C. (1977). Pragmatic deficits in the language of autistic adolescents. Journal of Pediatric Psychology, 2, 176-180.

Baltaxe, C., \& D’Angiola, N. (1992). Cohesion in the discourse interaction of autistic, specifically language-impaired, and normal children. Journal of Autism and Developmental Disorders, 22, 1-17.

Baron-Cohen, S. (1988). Social and pragmatic deficits in autism: Cognitive or affective? Journal of Autism and Developmental Disorders, 18, 37-402.

Baron-Cohen, S. (1989). The autistic child's theory of mind: A case of specific developmental delay. Journal of Child Psychology and Psychiatry, 30, 285-297.

Bramlett, R.K., Smith, B.L., \& Edmonds, J. (1994). A comparison of nonrefferred, learningdisabled, and mildly mentally retarded students utilizing the Social Skills Rating System. Psychology in the Schools, 31, 13-19.

Braverman, M., Fein, D., Lucci, D., \& Waterhouse, L. (1989). Affect comprehension in children with pervasive developmental disorders. Journal of Autism and Developmental Disorders, 19, 301-315.

Buchner, A., Erdfelder, E., \& Faul, F. (1997). How to Use G*Power. Retrieved December 8, 2006 from http://www.psycho.uniduesseldorf.de/aap/projects/gpower/how_to_use_ gpower.html 
Castles, E.E., \& Glass, C.R. (1986). Training in social and interpersonal problems solving skills for mildly and moderately retarded adults. American Journal of Mental Deficiency, 91, $35-42$.

Charman, T., Swettenham, J., Baron-Cohen, S., Cox, A., Baird, G., \& Drew, A. (1997). Infants with autism: An investigation of empathy, pretend play, joint attention and imitation. Developmental Psychology, 33, 781-789.

Christoff, K.A., \& Kelly, J.A. (1983). Social skills. In J.L. Matson \& S.E. Beuning (Eds.), Assessing the mentally retarded (pp. 181-206 ). New York: Grune and Stratton.

Cohen, J. (1965). Some statistical issues in psychological research. In B. B. Wolman (Ed.), Handbook of Clinical Psychology (pp. 95-121). New York: McGraw-Hill.

Cohen, D.J., Paul, R., \& Volkmar, F.R. (1986). Issues in the classification of pervasive developmental disorders: Toward DSM-IV. Journal of the American Academy of Child and Adolescent Psychiatry, 25, 213-220.

Dawson, G., Meltzoff, A., Osterling, J., Rinaldi, J., \& Brown, E. (1998). Children with autism fail to orient to naturally occurring social stimuli. Journal of Autism and Developmental Disorders, 28, 479-485.

Demaray, M.K., Ruffalo, S.L., Carlson, J., Busse, R.T., Olson, A.E., McManus, S.M., et al. (1995). Social skills assessment: A comparative evaluation of six published rating scales. School Psychology Review, 24, 648-671.

DiPerna, J.C., \& Volpe, R.J. (2005). Self-report on the Social Skills Rating System: Analysis of reliability and validity for an elementary sample. Psychology in the Schools, 42, 345-354.

Duncan, D., Matson, J.L., Bamburg, J.W., Cherry, K.E., \& Buckley, T. (1999). The relationship of self-injurious behavior and aggression to social skills in persons with severe and profound learning disability. Research in Developmental Disabilities, 20, 441-448.

Edelson, M.G. (2006). Are the majority of children with autism mentally retarded? A systematic evaluation of the data. Focus on Autism and Other Developmental Disabilities, 21, 66-83.

Eisenberg, L., \& Kanner, L. (1956). Early infantile autism, 1943-55. American Journal of Orthopsychiatry, 26, 556-566.

Elliott, S.N., \& Gresham, F.M. (1993). Social skills interventions for children. Behavior Modification, 17, 287-313.

Gillberg, C. (1989). Asperger's syndrome in 23 Swedish children. Developmental Medical and Child Neurology, 81, 520-531. 
Gillberg, C. (1990). Autism and pervasive developmental disorders. Journal of Child Psychology and Psychiatry, 26, 170-180.

Givens, T. (1978). The current status of three major techniques for the assessment of social competence in the diagnosis of the potentially retarded child. Southern Journal of Educational Research, 12, 75-84.

Gould, J. (1977). The use of the Vineland Social Maturity Scale, the Merrill-Palmer Scale of Mental Tests (non-verbal items) and the Reynell Developmental Language Scales with Children in contact with the services for severe mental retardation. Journal of Mental Deficiency Research, 21, 213-226.

Gresham, F.M., \& Elliott, S.N. (1984). Assessment and classification of children's social skills. A review of methods and issues. School Psychology Review, 13, 292-301.

Gresham, F.M., \& Elliott, S.N. (1990). Social Skills Rating System. Circle Pines, MN: American Guidance Service.

Gresham, F.M., Elliott, S.N., \& Black F. (1987). Teacher-rated social skills of mainstreamed mildly retarded and nonhandicapped children. School Psychology Review, 17, 78-88.

Guralnick, M.J. (1986). Children's social behavior: Development, assessment, and modification. Orlando, FL: Academic Press.

Happé, F.G. (1994). Wechsler IQ profile and theory of mind in autism: A research note. Journal of Child Psychology and Psychiatry, 35, 1461-1471.

Helsel, W.J., \& Matson, J.L. (1988). The relationship of depression to social skills and intellectual functioning in mentally retarded adults. Journal of Mental Deficiency Research, 32, 411-418.

Hermelin, B., \& O’Connor, N. (1970). Psychological experiments with autistic children. Oxford: Pergamon Press.

Hersen, M., \& Bellack, A.S. (1976). A multiple-baseline analysis of social-skills training in chronic schizophrenics. Journal of Applied Behavior Analysis, 9, 239-245.

Hersen, M., \& Bellack, A.S. (1977). Assessment of social skills. In A.R. Ciminero, K.S.Calhoun, \& H.E. Adams (Eds.), Handbook for behavioral assessment (pp. 509-554). New York: Wiley.

Hewitt, L.E. (1998). Influence of question type on response adequacy in young adults with autism. Journal of Communication Disorders, 31, 135-152.

Hobson, R.P. (1986a). The autistic child's appraisal of expressions of emotions. Journal of Child Psychology and Psychiatry, 27, 321-327. 
Hobson, R.P. (1986b). The autistic child's appraisal of expressions of emotions: A further study. Journal of Child Psychology and Psychiatry, 27, 671-680.

Hops, H. (1983). Children's social competence and skill: Current research practices and future directions. Behavior Therapy, 14, 3-18.

Jackson, C.T., Fein, D., Wolf, J., Jones, G., Hauck, M., Waterhouse, L., et al. (2003). Responses and sustained interactions in children with mental retardation and autism. Journal of Autism and Developmental Disorders, 33, 115-121.

Jacobson, J.W., \& Ackerman, L.J. (1990). Difference in adaptive functioning among people with autism or mental retardation. Journal of Autism and Developmental Disorders, 20, 205219.

Jarrold, C., Boucher, J., \& Smith, P. (1993). Symbolic play in autism: A review. Journal of Autism and Developmental Disorders, 23, 281-307.

Joseph, R.M., Tager-Flusberg, H., \& Lord, C. (2002). Cognitive profiles and socialcommunicative functioning in children with autism spectrum disorder. Journal of Child Psychology and Psychiatry, 43, 807-821.

Kanner, L. (1943). Autistic disturbances of affective contact. Nervous Child, 2, 217-250.

Kasari, C., Sigman, M., Mundy, P., \& Yirmiya, N. (1990). Affective sharing in the context of joint attention interactions of normal, autistic and mentally retarded children. Journal of Autism and Developmental Disorders, 20, 87-100

Kazdin, A. E., Esveldt-Dawson, K., \& Matson, J. L. (1983). The effects of instructional set on social skills performance among psychiatric inpatient children. Behavior Therapy, 14, 413-423.

Khouzam, H.R., El-Gabalawi, F., Piruani, N., \& Priest, F. (2004). Asperger's disorder: A review of its diagnosis and treatment. Comprehensive Psychiatry, 45, 184-191.

Kraijer, D. (2000). Review of adaptive behavior studies in mentally retarded persons with autism/pervasive developmental disorder. Journal of Autism and Developmental Disorders, 30, 39-47.

Kuhn, D.E., Matson, J.L., Mayville, E.A., \& Matson, M.L. (2001). The relationship of social skills as measured by the MESSIER to rumination in persons with profound mental retardation. Research in Developmental Disabilities, 22, 503-510.

Lam, K.S.L., Aman, M.G., \& Arnold, L.E. (2006). Neurochemical correlates of autistic disorder: A review of the literature. Research in Developmental Disabilities, 27, 254-289. 
Lambert, N.M., Wilcox, M.R., \& Gleason, W.P. (1974). The educationally retarded child. New York: Grune \& Stratton.

LeBlanc, L.A., Matson, J.L., Cherry, K.E., \& Bamburg, J.W. (1999). An examination of the convergent validity of the Matson Evaluation of Social Skills for Individuals with Severe Retardation (MESSIER) with sociometric rating. The British Journal of Developmental Disabilities, 45, 85-91.

Libet, J., \& Lewinsohn, P.M. (1973). Concept of social skill with special reference to the behavior of depressed persons. Journal of Consulting and Clinical Psychology, 40, 304312.

Lincoln, A.J., Allen, M., \& Kilman, A. (1995). The assessment and interpretation of intellectual abilities in people with autism. In E. Schopler \& G. Mesibov (Eds.), Learning and cognition in autism (pp. 89-117). New York: Plenum.

Loveland, K.A., \& Kelley, M.L. (1988). Development of adaptive behavior in adolescents and adults with autism and Down syndrome. American Journal on Mental Retardation, 93, 84-92.

Lyon, M.A., Albertus, C., Birkinbine, J., \& Naibi, J. (1996). A validity study of the Social Skills Rating System-Teacher Version with disabled and nondisabled preschool children. Perceptual and Motor Skills, 83, 307-316.

Marchetti, A., \& Campbell, V. (1990). Social Skills. In J.L. Matson (Ed.), Handbook of Behavior Modification with the Mentally Retarded (2 ${ }^{\text {nd }}$ ed., pp. 333-355) New York: Plenum Press.

Matson, J.L. (1989). The Matson Evaluation of Social Skills with Youngsters: Manual. Orland Park, IL: International Diagnostics Systems, Incorporated.

Matson, J.L. (1990). Handbook of behavior modification with the mentally retarded. ( $2^{\text {nd }}$ ed.). New York: Plenum Press.

Matson, J.L. (1994). Autism in children and adults: Etiology, assessment, and intervention. Pacific Grove, California: Brooks/Cole Publishing Company.

Matson, J.L. (1995). The Matson Evaluation of Social Skills for Individuals with Severe Retardation. Baton Rouge, LA: Scientific Publishers, Inc.

Matson, J.L. (2007). Current status of differential diagnosis for children with autism spectrum disorders. Research in Developmental Disabilities, 28, 119-128.

Matson, J.L., \& Barrett, R.P. (Eds.) (1993). Psychopathology in the mentally retarded (2 ${ }^{\text {nd }}$ ed.). Boston: Allyn and Bacon. 
Matson, J.L., \& Boisjoli, J. (2007). Differential diagnosis of PDD-NOS in children. Research in Autism Spectrum Disorders, 1, 75-84.

Matson, J.L., Boisjoli, J.A., González, M.L., Smith, K.R., \& Wilkins, J. (2007). Norms and cutoff scores for the Autism Spectrum Disorders Diagnosis for Adults with Intellectual Disability. Research in Autism Spectrum Disorders, 1, 330-338.

Matson, J.L., Carlisle, C.B., \& Bamburg, J.W. (1998). The convergent validity of the Matson Evaluation of Social Skills In Persons with Severe Retardation (MESSIER). Research in Developmental Disabilities, 19, 493-500.

Matson, J.L., Dixon, D.R., Matson, M.L., \& Logan, J.L. (2005). Classifying mental retardation and specific strength and deficit areas in severe and profoundly mentally retarded persons with the MESSIER. Research in Developmental Disabilities, 26, 41-45.

Matson, J.L., Esveldt-Dawson, K., \& Kazdin, A.E. (1983). Validation of methods for assessing social skills in children. Journal of Clinical Child Psychology, 12, 174-180.

Matson, J.L., Heinze, A., Helsel, W.J., Kapperman, G., \& Rotatori, A.F. (1986). Assessing social behaviors in the visually handicapped: The Matson Evaluation of Social Skills with Youngsters (MESSY). Journal of Clinical Child Psychology, 15, 78-87.

Matson, J.L., Helsel, W.J., Bellack, A.S., \& Senatore, V. (1983). Development of a rating scale to assess social skill deficits in mentally retarded adults. Applied Research in Mental Retardation, 4, 399-407.

Matson, J.L, Kazdin, A.E., \& Esveldt-Dawson, K. (1980). Training interpersonal skills among mentally retarded and socially dysfunctional children. Behaviour Research and Therapy, $18,419-427$.

Matson, J.L., LeBlanc, L.A., Weinheimer, B., \& Cherry, K.E. (1999). Reliability of the Matson Evaluation of Social Skills for Individuals with Severe Retardation (MESSIER). Behavior Modification, 23, 647-661.

Matson, J.L., Macklin, G.F., \& Helsel, W.J. (1985). Psychometric properties of the Matson Evaluation of Social Skills with Youngsters (MESSY) with emotional problems and self concept in deaf children. Journal of Behavior Therapy and Experimental Psychiatry, 16, 117-123.

Matson, J.L., Mayville, S.B., \& Laud, R.B. (2003). A system of assessment for adaptive behavior, social skills, behavioral function, medication side-effects, and psychiatric disorders. Research in Developmental Disabilities, 24, 75-81.

Matson, J.L., Mayville, E.A., Lott, J.D., Bielecki, J., \& Logan, R. (2003). A comparison of social and adaptive functioning in persons with psychosis, autism, and severe or profound mental retardation. Journal of Developmental and Physical Disabilities, 15, 57-66. 
Matson, J.L., \& Nebel-Schwalm, M.S. (2007). Comorbid psychopathology with autism spectrum disorders in children: An overview. Research in Developmental Disabilities, $28,567-579$.

Matson, J.L., Rotatori, A., \& Helsel, W.J. (1983). Development of a rating scale to measure social skills in children: The Matson Evaluation of Social Skills with Youngsters (MESSY). Behavior Research and Therapy, 21, 335-340.

Matson, J.L., \& Senatore, V. (1981). A comparison of traditional psychotherapy and social skills training for improving interpersonal functioning of mentally retarded adults. Behavior Therapy, 12, 369-382.

Matson, J.L., Smiroldo, B.B., \& Bamburg, J.W. (1998). The relationship of psychopathology to social skills in persons with severe and profound mental retardation. Journal of Intellectual Disability Research, 23, 137-145.

Matson, J.L., Stabinsky-Compton, L., \& Sevin, J.A. (1991). Comparison and item analysis of the MESSY for autistic and normal children. Research in Developmental Disabilities, 12, 361-369.

Matson, J.L., Wilkins, J., \& Ancona, M. (in press). Autism in adults with severe intellectual disability: An empirical study of symptom presentation. Journal of Intellectual and Developmental Disability

Matson, J.L., Wilkins, J., Boisjoli, J.A., \& Smith, K.R. (in press). The validity of the Autism Spectrum Disorders-Diagnosis for Intellectually Disabled Adults (ASD-DA). Research in Developmental Disabilities.

Matson, J.L., Wilkins, J., \& González, M.L. (2007). Reliability and factor structure of the Autism Spectrum Disorders-Diagnosis Scale for Intellectually Disabled Adults (ASD-DA). Journal of Physical and Developmental Disabilities, 19, 565-577.

Matson, J.L., Wilkins, J., Smith, K., \& Ancona, M. (in press). PDD-NOS symptoms in adults with intellectual disability: Toward an empirically oriented diagnostic model. Journal of Autism and Developmental Disorders.

Mayes, L., Volkmar, F., Hooks, M., \& Cicchetti, D. (1993). Differentiating pervasive developmental disorder not otherwise specified from autism and language disorders. Journal of Autism and Developmental Disorders, 23, 79-90.

McClintock, K., Hall, S., \& Oliver, C. (2003). Risk markers associated with challenging behaviours in people with intellectual disabilities: A meta-analytic study. Journal of Intellectual Disability Research, 47, 405-416.

McFall, R.M., \& Marston, A.R. (1970). An experimental investigation of behavior rehearsal in assertive training. Journal of Abnormal Psychology, 76, 295-303. 
McGee, G.G., Feldman, R.S., \& Morrier, M.J. (1997). Benchmarks of social treatment for children with autism. Journal of Autism and Developmental Disorders, 27, 353-364.

Mesibov, G. (1984). Social skills training with verbal autistic adolescents and adults: A program model. Journal of Autism and Developmental Disorders, 14, 395-403.

Mesibov, G. B., Adams, L. W., \& Schopler, E. (2000). Autism: A brief history. Psychoanalytic Inquiry, 20, 637-647.

Mundy, P. \& Crowson, M. (1997). Joint attention and early social communication: Implications for research on intervention with autism. Journal of Autism and Developmental Disorders, 27, 653-676.

Mundy, P., \& Sigman, M. (1989). Specifying the nature of the social impairment in autism. In G. Dawson (Ed.), Autism (pp. 3-21). New York: Guilford.

Mundy, P., Sigman, M., Ungerer, J., \& Sherman, T. (1986). Defining the social deficits of autism: The contribution of nonverbal communication measures. Journal of Child Psychology and Psychiatry, 27, 657-669.

Njardvik, U., Matson, J.L., \& Cherry, K.E. (1999). A comparison of social skill in adults with autistic disorder, pervasive developmental disorder not otherwise specified, and mental retardation. Journal of Autism and Developmental Disorders, 29, 287-295.

Ornitz, W.M., \& Ritvo E.R. (1968). Perceptual inconstancy in early infantile autism. Archives of General Psychology, 18, 76-98.

Paclawskyj, T.R., Rush, K.R., Matson, J.L., Cherry, K.E. (1999). Factor structure of the Matson Evaluation of Social Skills for Individuals with Severe Retardation (MESSIER). British Journal of Clinical Psychology, 38, 289-293.

Parkes, M. (1975). Psycho-social transitions: A field for study. Social Sciences and Medicine, 5, 101-115.

Paul, R., \& Cohen, D.J. (1985). Comprehension of indirect requests in adults with autistic disorder and mental retardation. Journal of Speech and Hearing Research, 28, 475-479.

Rodrigue, J.R., Morgan, S.B., \& Geffken, G.R. (1991). A comparative evaluation of adaptive behavior in children and adolescents with autism, Down syndrome, and normal development. Journal of Autism and Developmental Disorders, 21, 187-196.

Rutter, M. (1978). Diagnosis and definition of childhood autism. Journal of Autism and Childhood Schizophrenia, 8, 139-161.

Rutter, M. (1983). Cognitive deficits in the pathogenesis of autism. Journal of Child Psychology and Psychiatry, 24, 513-531. 
Schopler, E., Mesibov, G.B., \& Kunce, L.J. (1998). Asperger syndrome or high-functioning autism? New York: Plenum Press.

Sevin, J.A., Matson, J.L., Coe, D., Love, S.R., Matese, M., Benavidez, D.A. (1995). Empirically derived subtypes of pervasive developmental disorder. Journal of Autism and Developmental Disorders, 25, 561-578.

Shattuck, P.T., Seltzer, M.M., Greenberg, J.S., Orsmond, G.I., Bolt, D., King, S., et al. (2007). Changes in autism and maladaptive behaviors in adolescents and adults with an Autism Spectrum Disorder. Journal of Autism and Developmental Disorders, 37, 1735-1747.

Sigman, M.D., Kasari, C., Kwon, J., \& Yirmiya, N. (1992). Responses to the negative emotions of others by children with autism, children with mental retardation, and normal children. Child Development, 63, 796-807.

Sparrow, S.S., Balla, D.A., \& Cicchetti, D.V. (1984). Vineland Adaptive Behavior Scales: Interview Edition, Survey Form manual. Circle Pines, MN: American Guidance Service.

Stella, J., Mundy, P., \& Tuchman, R. (1999). Social and nonsocial factors in the Childhood Autism Scale. Journal of Autism and Developmental Disorders, 29, 307-317.

Stone, W., \& Caro-Martinez, L. (1990). Naturalistic observation of spontaneous communication in autistic children. Journal of Autism and Developmental Disorders, 20, 437-453.

Swettenham, J., Baron-Cohen, S., Charman, T., Cox, A., Baird, G., Drew, A., et al. (1998). The frequency and distribution of spontaneous attention shifts between social \& non-social stimuli in autistic, typically developing and nonautistic developmentally delayed infants. Journal of Child Psychology and Psychiatry, 39, 747-753.

Tabachnick, B.G., \& Fidell, L.S. (2001). Using multivariate statistics $\left(4^{\text {th }}\right.$ ed.). Needham Heights, MA: Allyn and Bacon.

Tager-Flusberg, H., \& Anderson, M. (1991). The development of contingent discourse ability in autistic children. Journal of Child Psychiatry, 32, 1123-1134.

Tidmarsh, L., \& Volkmar, F.R. (2003). Diagnosis and epidemiology of Autism Spectrum Disorders. Canadian Journal of Psychiatry, 48, 517-525.

Towbin, K. (1997). Pervasive developmental disorders not otherwise specified. In D.J. Cohen and F.R. Volkmar (Eds.), Handbook of autism and pervasive developmental disorders (2nd ed., pp. 123-147). New York: Wiley.

Van Bourgondien, M.E., \& Elgar, S. (1990). The relationship between existing residential services and the needs of autistic adults. Journal of Autism and Developmental Disorders, 20, 299-308. 
Van Hasselt, V., Hersen, M., \& Bellack, A.S. (1981). The validity of role play tests for assessing social skills in children. Behavior Therapy, 12, 202-216.

Van Hasselt, V.B., Hersen, M., \& Kazdin, A.E. (1985). Assessment of social skills in visuallyhandicapped adolescents. Behavior Research and Therapy, 23, 53-63.

Volkmar, F.R., Carter, A., Sparrow, S.S., \& Cicchetti, D.V. (1993). Quantifying social development in autism. Journal of the American Academy of Child and Adolescent Psychiatry, 32, 627-632.

Volkmar, F. R., Klin, A., \& Cohen, D. J. (1997). Diagnosis and classification of autism and related conditions: Consensus and issues. In D. J. Cohen \& F. R. Volkmar (Eds.), Handbook of autism and pervasive developmental disorders $\left(2^{\text {nd }}\right.$ ed., pp. 5-40). New York: John Wiley \& Sons, Inc.

Volkmar, F.R., Sparrow, S.S., Goudreau, D., Cicchetti, D.V., Paul, R., \& Cohen, D. (1987). Social deficits in autism: An operational approach using the Vineland Adaptive Behavior Scales. Journal of the American Academy of Child and Adolescent Psychiatry, 26, 156161.

Wahlberg, T., \& Jordan, S. (2001). A case study in the dynamics of autism. In T. Wahlberg, F. Obiakor, S. Burkhardt, \& A.F. Rotatori (Eds.), Autistic spectrum disorders: Educational and clinical interventions. Advances in special education (Vol. 14, pp. 53-65). Oxford, England: Elsevier.

Wilkins, J., \& Matson, J.L. (2007). Social skills. In J.L. Matson (Ed.), Handbook of assessment in persons with intellectual disability (pp. 315-357). San Diego, CA: Elsevier Science, Inc.

Wing, L. (1997). Syndromes of Autism and Atypical Development. In D.J. Cohen \& F.R. Volkmar (Eds.), Handbook of autism and pervasive developmental disorders $\left(2^{\text {nd }}\right.$ ed., pp. 148-172). New York: John Wiley \& Sons, Inc.

Wing, L., \& Gould, J. (1979). Severe impairments of social interaction and associated abnormalities in children: Epidemiology and classification. Journal of Autism and Developmental Disorders, 9, 11-29.

World Health Organization (1992). International Classification of Diseases (10 ${ }^{\text {th }}$ ed.). Geneva, Switzerland: Author. 


\section{VITA}

Jonathan Wilkins earned a Bachelor of Arts degree in psychology in June of 2002 from Carleton College in Northfield, Minnesota. He is currently fulfilling the requirements for Doctor of Philosophy in clinical psychology from Louisiana State University under the supervision of Dr. Johnny Matson. 